
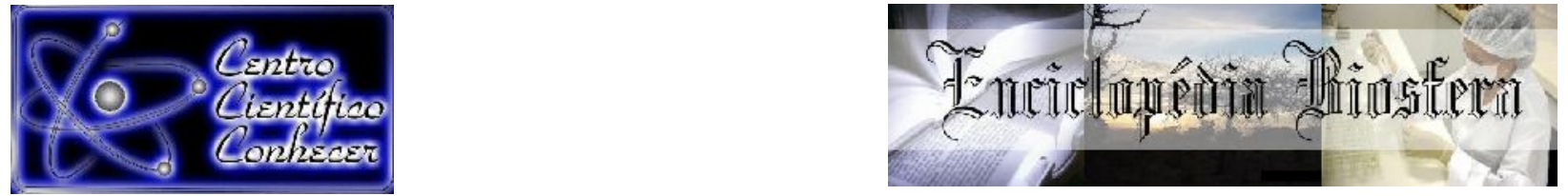

\title{
IMPACTOS AO MEIO AMBIENTE E A SAÚDE DECORRENTES DO DESCARTE DE PILHAS E BATERIAS PORTÁTEIS EM GOIÂNIA - GOIÁS
}

\author{
Kassia Francielly Soares de Oliveira Martins ${ }^{{ }^{*}}$, Julio Cezar Rubin de Rubin ${ }^{2}$, Sandra \\ Regina Longhin ${ }^{3}$. \\ 1,2Pontifícia Universidade Católica de Goiás, Goiânia, Goiás, Brasil. \\ ${ }^{3}$ Pontifícia Universidade Católica de Goiás/Instituto Federal de Goiás, Goiânia, \\ Goiás, Brasil. \\ *Autor correspondente: kassia.eng@gmail.com
}
Recebido em: 06/04/2018 - Aprovado em: 10/06/2018 - Publicado em: 20/06/2018 DOI: 10.18677/EnciBio 2018A116

\begin{abstract}
RESUMO
Tendo como ponto de partida o descarte inadequado de pilhas e baterias no Resíduo Sólido Urbano (RSU) do município de Goiânia, o objetivo desta pesquisa é avaliar o potencial tóxico dos metais provenientes de pilhas e baterias descartadas no Aterro Sanitário de Goiânia e diagnosticar a forma de descarte destes resíduos. Com isso, abordou-se nesta pesquisa os resultados obtidos através dos parâmetros cádmio, chumbo e mercúrio em função das análises do chorume do Aterro Sanitário de Goiânia e do efluente da ETE Dr. Hélio Seixo de Brito, além da estimativa de pilhas e baterias recicladas no Brasil e em Goiás. Os resultados evidenciam a problemática futura, porquanto, pilhas e baterias decompõe-se a partir de 100 anos, sendo que há 35 anos a área do Aterro Sanitário de Goiânia é utilizada para disposição de RSU. Portanto, estes resíduos estão em processo de decomposição e os teores destes parâmetros tendem a se elevarem. Sendo essa questão o efeito de uma causa, descarte ambientalmente inadequado, evidenciada nas estimativas de reciclagem de pilhas e baterias, no período de 2012 a 2016, no Brasil e no estado de Goiás, sendo, $55,45 \%$ e $0,65 \%$, respectivamente. Todo este escopo aponta a importância de se ampliar os programas de educação ambiental para solucionar a problemática do descarte de pilhas e baterias.
\end{abstract}

PALAVRAS-CHAVE: Metais tóxicos, pilhas e baterias, saúde.

\section{IMPACTS TO THE ENVIRONMENT AND HEALTH WITH THE DISPOSAL OF PORTABLE BATTERIES IN GOIÂNIA - GO}

\begin{abstract}
Having as a starting point the inappropriate disposal of batteries in the Urban Solid Waste (USW) of the municipality of Goiânia, the objective of this research is to evaluate the toxic potential of metals from batteries in the Landfill of Goiânia and to diagnose the way of disposal of this residue. In this study, the results obtained by the parameters cadmium, lead and mercury were investigated in relation to the slurry analysis of the Sanitary Landfill of Goiânia and the ETE effluent Dr. Hélio Seixo de Brito, as well as the estimate of batteries recycled in Brazil and Goiás. The results
\end{abstract}


show the future problem, because, batteries decompose from 100 years and the Landfill of Goiânia beging there 35 years with the area disposal of WUS. Therefore, these residues are in the process of decomposition and the tenor of these parameters tend to increase. This question is the effect of a cause, environmentally inappropriate disposal, evidenced in battery recycling estimates, between 2012 and 2016, in Brazil and the state of Goiás, being $55.45 \%$ and $0,65 \%$ respectively. This whole scope points to the importance of expanding environmental education programs to solve the problem of the disposal of batteries.

KEYWORDS: Batteries, health, toxic metals.

\section{INTRODUÇÃO}

Em 1800 o físico italiano Alessandro Volta construiu sua primeira unidade de potencial elétrico, o Volt, sendo o personagem mais aceito como o inventor das pilhas. Em homenagem ao cientista a unidade de potencial elétrico recebeu o nome "Volt". Em 1868 o engenheiro francês George Leclanché desenvolveu a pilha de carbono-zinco $(\mathrm{Zn}-\mathrm{C})$, que teve seu uso propagado. O desenvolvimento progrediu em alta escala, sendo que no início do século XX os Estados Unidos produziram cerca de dois milhões de pilhas e baterias. No decorrer do século novas invenções foram surgindo, o rádio doméstico em 1920 e a partir dos anos 60 vários outros equipamentos elétricos e eletrônicos portáteis ficaram disponíveis no mercado com o transcorrer do tempo (ORSOLON, 2010).

A precaução sobre o descarte e suas consequências surgiu no final da década de 1970, onde atentaram-se aos perigos de se descartar baterias e pilhas usadas junto com o resíduo comum, hoje identificado como resíduo sólido urbano (RSU). Até a década de 1980, normalmente, utilizava-se para uso doméstico as baterias em forma de bastonetes, principalmente de $\mathrm{Zn}-\mathrm{C}$, as quais, quando exauridas eram destinadas junto com o resíduo domiciliar. Em alguns países da Europa, no final dessa década, observou-se os perigos a que estavam sujeitos as pessoas e o ambiente diante da disposição inadequada de tais resíduos, fato que incentivou a pesquisa de métodos de gerenciamento, tendo como objetivo minimizar os riscos sanitários e ambientais (REIDLER; GÜNTHER, 2003).

De forma simplificada, as baterias têm como princípio básico converter energia química em energia elétrica utilizando um metal como combustível. Sua composição pode variar dentre os seguintes metais: chumbo $(\mathrm{Pb})$, cádmio $(\mathrm{Cd})$, mercúrio $(\mathrm{Hg})$, níquel $(\mathrm{Ni})$, prata $(\mathrm{Ag})$, lítio $(\mathrm{Li})$, zinco $(\mathrm{Zn})$, manganês $(\mathrm{Mn})$ e seus compostos. As substâncias das pilhas que contêm tais metais possuem características de corrosividade, reatividade e toxicidade e são classificadas como Resíduos Perigosos - Classe I de acordo com a Associação Brasileira de Normas Técnicas (ABNT) (MONTEIRO et al., 2001).

Tendo como ponto de partida o descarte de pilhas e baterias no RSU do município de Goiânia, o objetivo desta pesquisa foi avaliar o potencial tóxico dos metais provenientes de pilhas e baterias descartadas no Aterro Sanitário de Goiânia e diagnosticar a forma de descarte destes resíduos.

\section{MATERIAL E MÉTODOS}

\section{Análise comparativa}

A caracterização do ciclo representativo do descarte de pilhas e baterias portáteis em Goiânia é representada por 10 etapas, como ilustra a Figura 1. Inicia-se 
pela população "etapa 1" que demanda uma produção de diversos artefatos, inclusive a geração de pilhas e baterias "etapa 2" para fornecer energia aos equipamentos consumidos pela população "etapa 3", mas a utilização das pilhas e baterias é por um determinado tempo, em função, da vida útil "etapa 4" das pilhas ou baterias.

A geração de resíduos sólidos "etapa 5" está relacionada com o consumo e a vida útil destes produtos, além do aumento da população está vinculada a geração de RSU no Brasil. Dado que, as pilhas e baterias possuem uma vida útil e depois de exauridas tornam-se resíduos sólidos, há duas formas de descarte, o ambientalmente adequado "etapa 6a" ou inadequado "etapa 6b"; no primeiro caso será destinada a reciclagem "etapa 7a" e no segundo ao Aterro Sanitário "etapa 7b".

Em Goiânia, as pilhas e baterias descartadas de forma ambientalmente adequada, são recebidas nos pontos fornecidos pelo Programa Abinee Recebe Pilhas (PARP); o sítio online do programa, informa a localização de 17 pontos para coleta. Entretanto, as descartadas no resíduo comum são encaminhadas ao Aterro Sanitário de Goiânia, no qual, transporta seu chorume "etapa 8" para a ETE Dr. Hélio Seixo de Britto "etapa 9" onde realiza-se o tratamento do chorume juntamente com o efluente, depois de passar pelo processo de tratamento primário avançado, o efluente é lançado no Rio Meia Ponte "etapa 10", importante curso de água no estado de Goiás.

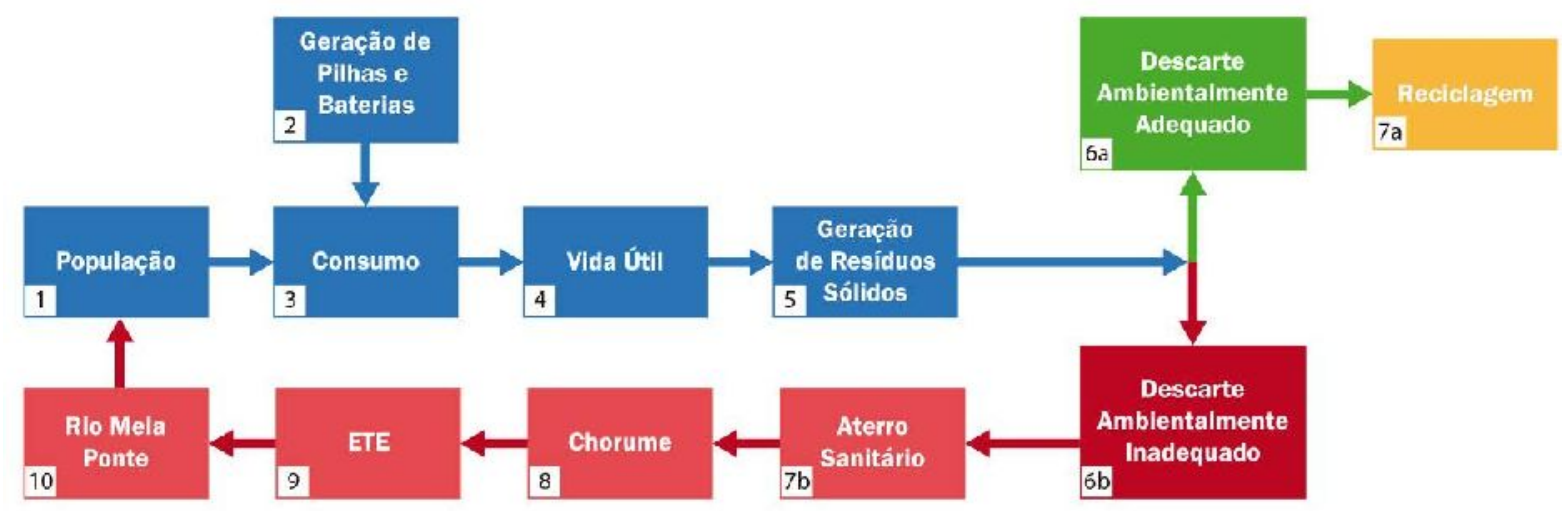

FIGURA 1 - Ciclo representativo do descarte de pilhas e baterias na cidade de Goiânia.

A Figura 2 apresenta a localização do município de Goiânia e seus confrontantes Goianira, Santo Antônio de Goiás, Nerópolis, Goianápolis, Bonfinópolis, Senador Canêdo, Caldazinha, Aparecida de Goiânia, Abadia de Goiás e Trindade. No município de Goiânia é destacado o Rio Meia Ponte, corpo receptor do efluente tratado da ETE, o ponto 1 e o ponto 2, representando respectivamente, 0 Aterro Sanitário de Goiânia e a ETE Dr. Hélio Seixo de Brito.

A ETE, recebe o chorume gerado pelo Aterro Sanitário de Goiânia e transporta os resíduos sólidos proveniente do processo de tratamento ao Aterro Sanitário de Goiânia, e por esta razão, será analisado os teores de metais do lodo oriundo dos decantadores da ETE, do efluente final, a montante e a jusante do ponto de descarte do efluente da ETE no Rio Meia Ponte, bem como, os teores de metais do chorume; tal relação é ilustrada na Figura 3. As análises serão avaliadas em função dos padrões estabelecido pela Resolução Conama n`357 de 2005, Resolução Conama 
n`375 de 2006, Resolução Conama n`397 de 2008, Resolução Conama $n^{\circ} 430$ de 2011, e a Legislação Estadual, Lei n`8544 de 1978 (BRASIL, 1978, 2005, 2006, 2008a, 2011).

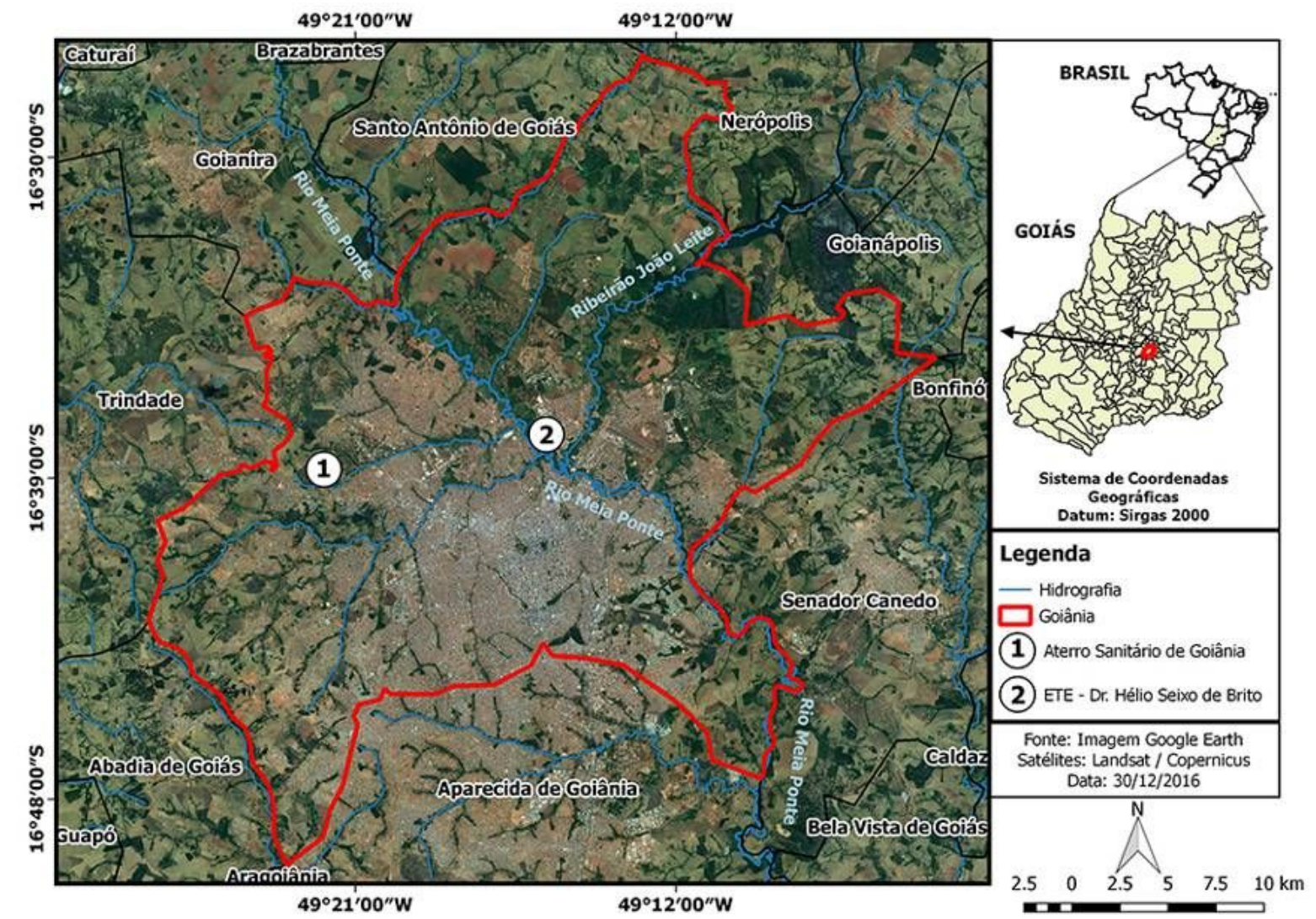

FIGURA 2 - Localização do Aterro Sanitário de Goiânia e da ETE Dr. Hélio Seixo de Britto.

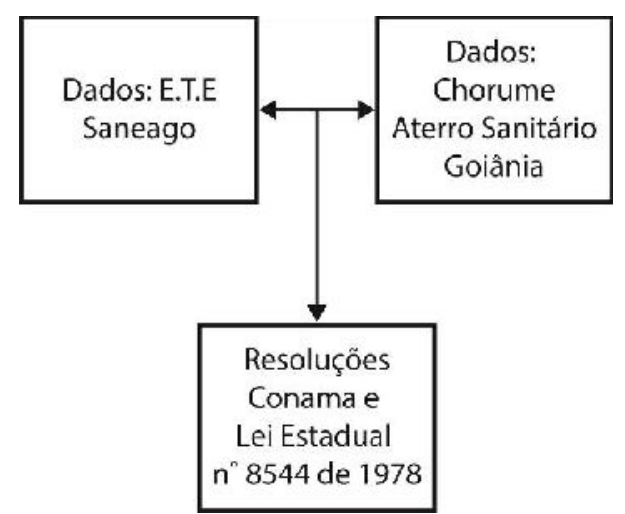

FIGURA 3 - Relação das fontes de dados coletados.

Desde 1998 o Instituto Brasileiro de Geografia e Estatística (IBGE) publica anualmente os resultados da Pesquisa Industrial Produto (PIA-Produto), na qual informa a produção na indústria brasileira, definidos de acordo com nomenclatura articulada com a Classificação Nacional de Atividades Econômicas - CNAE e com a Nomenclatura Comum do Mercosul - NCM e fornece dados que serão abordados 
nesta pesquisa, como: partes e peças para pilhas, baterias ou acumuladores elétricos, exceto para veículos, no Brasil (IBGE, 2017).

Os dados obtidos pelo IBGE serão relacionados com as coletas de pilhas e baterias recicladas no Brasil. Esta informação é proveniente do PARP, fundado em 2010 pelos fabricantes e importadores de pilhas e baterias portáteis, com o objetivo de receber estes resíduos e encaminhá-los a reciclagem. No sítio online da Abinee, disponibiliza-se a página do PARP, na qual, oferta-se a informação do peso total já coletado em kg, além da opção de selecionar o estado e a cidade para conhecer os pontos de coleta na cidade desejada (ABINEE, 2010).

A Figura a seguir ilustra a associação entre os dados disponíveis quanto a fabricação e comercialização de pilhas e baterias no Brasil e a coleta e reciclagem pelo PARP. Desta forma é possível ser estimar o percentual destinado a reciclagem.

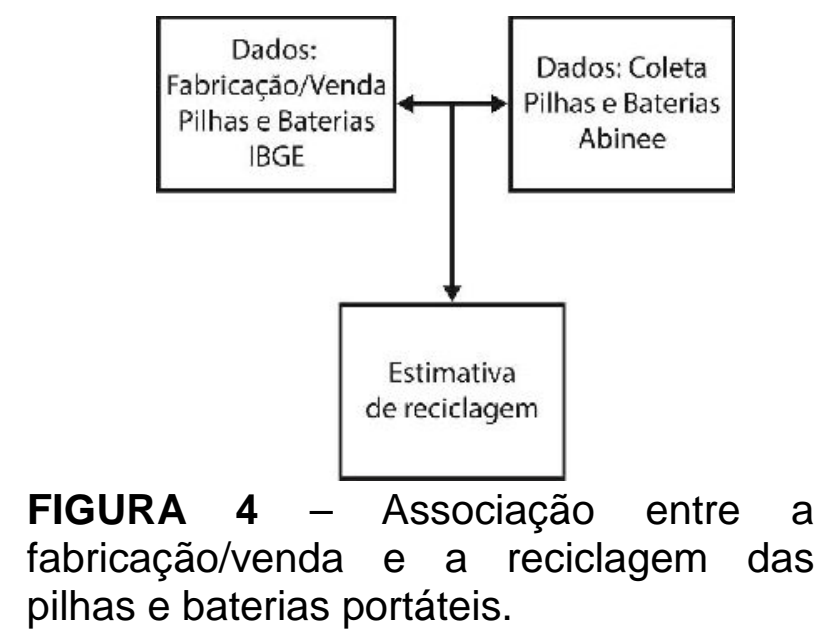

Por meio da Pesquisa Industrial Anual - Produto (PIA-Produtos) se obteve o peso das partes e peças para pilhas, baterias ou acumuladores elétricos, exceto para veículos, no Brasil referente aos anos de 2010 a 2013. Devido ao período estabelecido nesta pesquisa ser de 2012 a 2016, realizou-se uma estimativa dos anos de 2014 a 2016 determinando a Taxa Média de Crescimento em Intervalos Regulares de Tempo conforme a Equação 1, proposta por Farris et al., (2010), na qual, $f$ e $i$ são valor final e inicial, respectivamente, e a é o número de anos.

Taxa de crescimento Equação 1

\section{Coleta dos dados}

Para acessar as análises do chorume do Aterro Sanitário de Goiânia encaminhou-se um ofício a Companhia de Urbanização de Goiânia (Comurg) requisitando os teores de metais (cádmio, chumbo e mercúrio) do chorume do Aterro Sanitário de Goiânia no estado bruto e tratado no período de 2005 a 2012.

Protocolou-se na Companhia Saneamento de Goiás S.A. (Saneago) um ofício solicitando o acesso das análises dos teores de metais (cádmio, chumbo e mercúrio) do lodo oriundo dos decantadores, do efluente final, a montante e a jusante do ponto de descarte do efluente da ETE Dr. Hélio Seixo de Britto no Rio Meia Ponte e do chorume do Aterro Sanitário de Goiânia, referente ao período 2012 a 2016 . As análises foram realizadas pelos métodos determinados pelo American Public Health Association (APHA) e American Water Works Association (AWWA). Dentre os 
parâmetros disponíveis, será considerado o chumbo, cádmio e mercúrio, pois a Resolução Conama $n^{\circ} 401$, de 4 de novembro de 2008, estabelece o limite máximo destes parâmetros nas pilhas e baterias comercializadas em território nacional (BRASIL, 2008b).

A Figura 5 demonstra os pontos $a, b, c, d$ referenciando os locais onde são coletadas as amostras para realização das análises. As descrições são: i) ponto a, lodo proveniente do decantador da ETE ii) ponto $b$, efluente final da ETE iii) ponto $c$, a montante do ponto de descarte do efluente da ETE no Rio Meia Ponte iv) ponto $d$ a jusante do ponto de descarte do efluente da ETE no Rio Meia Ponte. Assim, tem-se as análises em função das etapas do tratamento primário avançado da ETE Dr. Hélio Seixo de Brito e a comparação dos parâmetros antes e depois do lançamento do efluente tratado no Rio Meia Ponte.

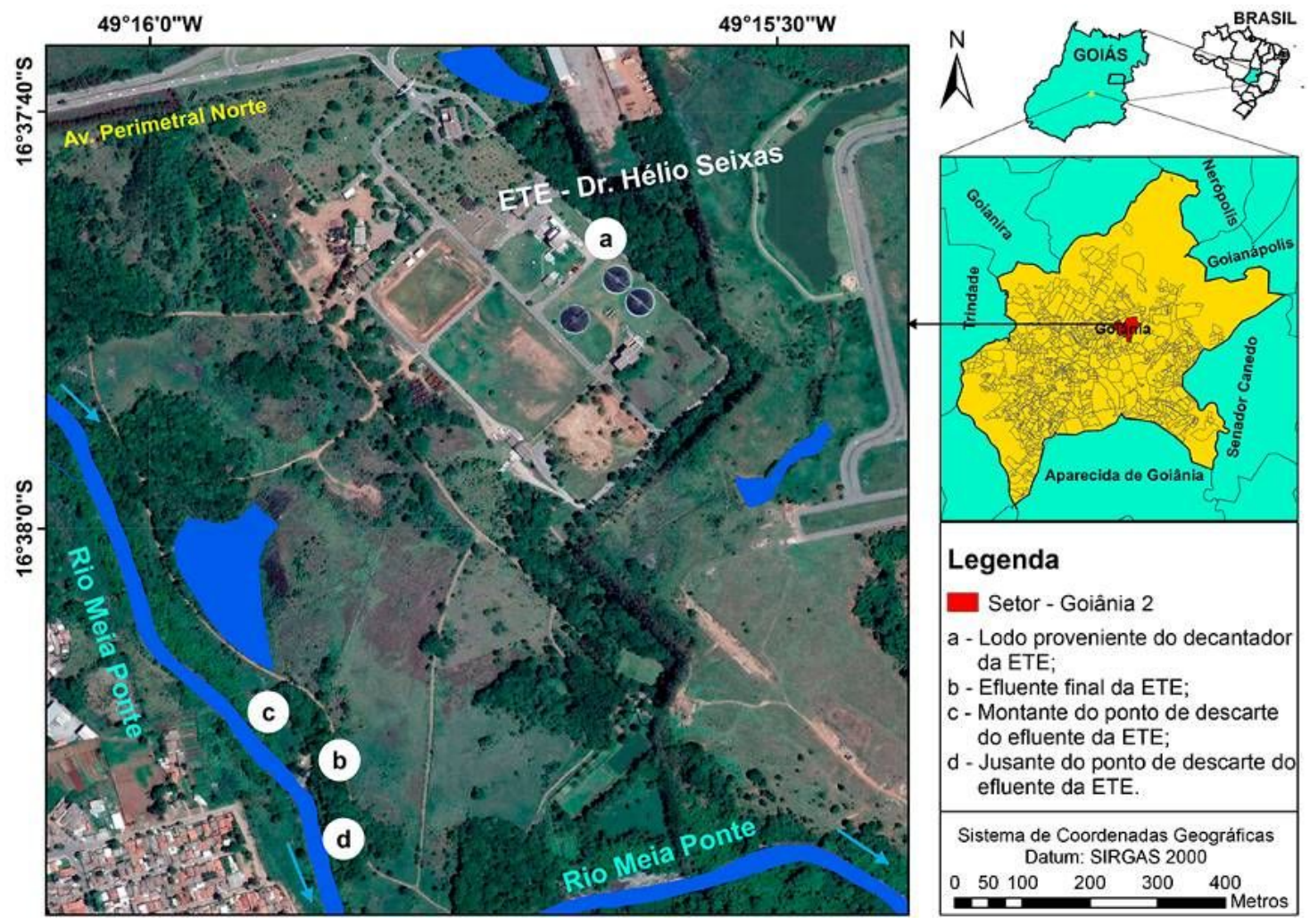

FIGURA 5 - Pontos de coleta do efluente para análises.

\section{RESULTADOS}

\section{Análises dos metais}

Realizou-se um comparativo das análises laboratoriais fornecidas pela ETE Dr. Hélio Seixo de Britto, nos pontos: lodo proveniente do decantador, efluente final, montante e jusante do ponto de descarte da ETE, com o valor máximo permitido (VMP) da legislação e resoluções pertinentes, os resultados estão apresentados na Tabela 1, Tabela 2, Tabela 3 e Tabela 4 com a descrição dos dados. Obteve-se também a análise da lagoa anaeróbia e facultativa do chorume do Aterro Sanitário de Goiânia referente ao ano de 2015, demonstrada na Tabela 5 e Tabela 6.

Os dados referentes ao lodo apresentado na Tabela 1 referem-se ao material removido do decantador primário da ETE, através da sedimentação dos sólidos 
suspensos sedimentáveis. Realizam-se análises e compararam-se os parâmetros cádmio, chumbo e mercúrio com a Resolução do Conama n`375/2006 que estabelece a concentração máxima destes parâmetros no lodo (BRASIL, 2006). Verifica-se que todos os parâmetros se encontram dentro do VMP. Sendo que, o maior teor do cádmio foi em 2012, do chumbo e do mercúrio em 2016.

TABELA 1 - Análises do lodo proveniente do decantador da ETE Dr. Hélio Seixo de Britto.

\begin{tabular}{|c|c|c|c|c|}
\hline Ano & Parâmetros & Resultado Lodo & VMP CONAMA 375/2006 & Unidade \\
\hline \multirow{3}{*}{2012} & Cádmio & 1 & 39 & \multirow{3}{*}{$\mathrm{mg} / \mathrm{kg}$} \\
\hline & Chumbo & 13 & 300 & \\
\hline & Mercúrio & 0,75 & 2 & \\
\hline \multirow{3}{*}{2013} & Cádmio & 0,1 & 39 & \multirow{3}{*}{$\mathrm{mg} / \mathrm{kg}$} \\
\hline & Chumbo & 18,5 & 300 & \\
\hline & Mercúrio & 1,06 & 17 & \\
\hline \multirow{3}{*}{2014} & Cádmio & 0,1 & 39 & \multirow{3}{*}{$\mathrm{mg} / \mathrm{kg}$} \\
\hline & Chumbo & 15,5 & 300 & \\
\hline & Mercúrio & 0,67 & 17 & \\
\hline \multirow{3}{*}{2015} & Cádmio & 0,09 & 39 & \multirow{3}{*}{$\mathrm{Mg} / \mathrm{kg}$} \\
\hline & Chumbo & 10,39 & 300 & \\
\hline & Mercúrio & 1,11 & 17 & \\
\hline \multirow{3}{*}{2016} & Cádmio & 0,26 & 39 & \multirow{3}{*}{$\mathrm{mg} / \mathrm{kg}$} \\
\hline & Chumbo & 19,73 & 300 & \\
\hline & Mercúrio & 1,21 & 17 & \\
\hline
\end{tabular}

Legenda: V.M.P. - Valor Máximo Permitido.

Depois que o efluente passa por todas as etapas do tratamento primário avançado da ETE Dr. Hélio Seixo de Brito, tem-se o efluente final que será lançado no corpo receptor. $O$ resultado apresentado na Tabela 2 do efluente final nos anos, 2012, 2013, 2015 e 2016 dos parâmetros, cádmio, chumbo e mercúrio são avaliados em função da Lei $n^{\circ} 8544 / 1978$ que estabelece os padrões de lançamento de efluentes no estado de Goiás e a Resolução Conama n 430/2011 dispõe sobre as condições e padrões de lançamento de efluentes em corpos de água receptores no Brasil. (BRASIL, 1978, 2011). Dentre os parâmetros, o mercúrio esteve no limite do VMP em 2013 e sobressaiu em 2015, pois o VMP é $0,01 \mathrm{mg} / \mathrm{L}$ e o resultado foi de $0,013 \mathrm{mg} / \mathrm{L}$. Os demais parâmetros se mantiveram dentro do VMP.

TABELA 2 - Análises do efluente final da ETE Dr. Hélio Seixo de Britto.

\begin{tabular}{|c|c|c|c|c|c|}
\hline \multirow{2}{*}{ Ano } & Parâmetros & $\begin{array}{c}\text { Resultados } \\
\text { Efluente } \\
\text { Final }\end{array}$ & $\begin{array}{c}\text { VMP: Lei } \\
\text { 8544/1978 e } \\
\text { CONAMA } \\
\text { 430/2011 }\end{array}$ & $\begin{array}{c}\text { VMP: } \\
\text { CONAMA } \\
\text { 430/2011 }\end{array}$ & \multirow{2}{*}{ Unidade } \\
\hline \multirow{2}{*}{2012} & Cádmio & 0,001 & 0,20 & 0,20 & \multirow{2}{*}{$\mathrm{mg} / \mathrm{L}$} \\
\cline { 2 - 5 } & Chumbo & 0,001 & 0,50 & 0,50 & \\
\cline { 2 - 5 } & Mercúrio & 0,001 & 0,01 & 0,01 & \multirow{2}{*}{$\mathrm{mg} / \mathrm{L}$} \\
\hline 2013 & Cádmio & 0,001 & 0,20 & 0,20 & \\
\hline
\end{tabular}




\begin{tabular}{|c|c|c|c|c|c|}
\hline Ano & Parâmetros & $\begin{array}{l}\text { Resultados } \\
\text { Efluente } \\
\text { Final }\end{array}$ & $\begin{array}{c}\text { VMP: Lei } \\
\text { 8544/1978 e } \\
\text { CONAMA } \\
\text { 430/2011 }\end{array}$ & $\begin{array}{l}\text { VMP: } \\
\text { CONAMA } \\
\text { 430/2011 }\end{array}$ & Unidade \\
\hline & Chumbo & 0,001 & 0,50 & 0,50 & \\
\hline & Mercúrio & 0,01 & 0,01 & 0,01 & \\
\hline \multirow{3}{*}{2014} & Cádmio & ND & 0,20 & 0,20 & \multirow{3}{*}{$\mathrm{mg} / \mathrm{L}$} \\
\hline & Chumbo & ND & 0,50 & 0,50 & \\
\hline & Mercúrio & ND & 0,01 & 0,01 & \\
\hline \multirow{3}{*}{2015} & Cádmio & 0,002 & 0,20 & 0,20 & \multirow{3}{*}{$\mathrm{mg} / \mathrm{L}$} \\
\hline & Chumbo & 0,001 & 0,50 & 0,50 & \\
\hline & Mercúrio & 0,013 & 0,01 & 0,01 & \\
\hline \multirow{3}{*}{2016} & Cádmio & 0,0006 & 0,20 & 0,20 & \multirow{3}{*}{$\mathrm{mg} / \mathrm{L}$} \\
\hline & Chumbo & 0,0001 & 0,50 & 0,50 & \\
\hline & Mercúrio & 0,0011 & 0,01 & 0,01 & \\
\hline
\end{tabular}

Legenda: V.M.P. - Valor Máximo Permitido. ND - Não Determinado.

A Tabela 3 apresenta os dados do ponto de coleta antes do lançamento do efluente da ETE no Rio Meia Ponte, ou seja, a montante. Com isso, obteve-se os dados de 2013 a 2015 dos parâmetros cádmio, chumbo e mercúrio e analisou-se, em função da Lei $n^{\circ} 8544 / 1978$ do estado de Goiás e a Resolução Conama n ${ }^{\circ}$ $357 / 2005$ que dispõe sobre a classificação dos corpos de água e diretrizes ambientais para o seu enquadramento (BRASIL, 1978, 2005).

TABELA 3 - Análises a montante do ponto de descarte da ETE Dr. Hélio Seixo de Britto.

\begin{tabular}{|c|c|c|c|c|c|}
\hline Ano & Parâmetros & $\begin{array}{l}\text { Resultados } \\
\text { Montante }\end{array}$ & $\begin{array}{c}\text { VMP: Lei } \\
8544 / 1978\end{array}$ & $\begin{array}{c}\text { VMP: } \\
\text { CONAMA } \\
357 / 2005\end{array}$ & Unidade \\
\hline \multirow{3}{*}{2012} & Cádmio & ND & 0,01 & 0,001 & \multirow{3}{*}{$\mathrm{mg} / \mathrm{L}$} \\
\hline & Chumbo & ND & 0,05 & 0,01 & \\
\hline & Mercúrio & ND & 0,002 & 0,0002 & \\
\hline \multirow{3}{*}{2013} & Cádmio & 0,0019 & 0,01 & 0,001 & \multirow{3}{*}{$\mathrm{mg} / \mathrm{L}$} \\
\hline & Chumbo & 0,0063 & 0,05 & 0,01 & \\
\hline & Mercúrio & 0,0003 & 0,002 & 0,0002 & \\
\hline \multirow{3}{*}{2014} & Cádmio & 0,0006 & 0,01 & 0,001 & \multirow{3}{*}{$\mathrm{mg} / \mathrm{L}$} \\
\hline & Chumbo & 0,0052 & 0,05 & 0,01 & \\
\hline & Mercúrio & 0,0030 & 0,002 & 0,0002 & \\
\hline \multirow{3}{*}{2015} & Cádmio & 0,0003 & 0,01 & 0,001 & \multirow{3}{*}{$\mathrm{mg} / \mathrm{L}$} \\
\hline & Chumbo & 0,0001 & 0,05 & 0,01 & \\
\hline & Mercúrio & 0,0014 & 0,002 & 0,0002 & \\
\hline \multirow{3}{*}{2016} & Cádmio & ND & 0,01 & 0,001 & \multirow{3}{*}{$\mathrm{mg} / \mathrm{L}$} \\
\hline & Chumbo & ND & 0,05 & 0,01 & \\
\hline & Mercúrio & ND & 0,002 & 0,0002 & \\
\hline
\end{tabular}

Legenda: V.M.P. - Valor Máximo Permitido. ND - Não Determinado. 
Na Tabela 4 demonstra as análises de 2013 a 2015 dos parâmetros cádmio, chumbo e mercúrio, à jusante (após) do ponto de descarte do efluente da ETE Dr. Hélio Seixo de Brito. Assim como no ponto a montante, as análises foram avaliadas em função da Lei $n^{\circ}$ 8544/1978 do estado de Goiás e a Resolução Conama n 357/2005 (BRASIL, 1978, 2005).

TABELA 4 - Análises a jusante do ponto de descarte da ETE Dr. Hélio Seixo de Britto.

\begin{tabular}{|c|c|c|c|c|c|}
\hline Ano & Parâmetros & $\begin{array}{l}\text { Resultados } \\
\text { Jusante }\end{array}$ & $\begin{array}{l}\text { VMP: Lei } \\
8544 / 1978\end{array}$ & $\begin{array}{c}\text { VMP: } \\
\text { CONAMA } \\
357 / 2005\end{array}$ & Unidade \\
\hline \multirow{3}{*}{2012} & Cádmio & ND & 0,01 & 0,001 & \multirow{3}{*}{$\mathrm{mg} / \mathrm{L}$} \\
\hline & Chumbo & ND & 0,05 & 0,01 & \\
\hline & Mercúrio & ND & 0,002 & 0,0002 & \\
\hline \multirow{3}{*}{2013} & Cádmio & 0,0014 & 0,01 & 0,001 & \multirow{3}{*}{$\mathrm{mg} / \mathrm{L}$} \\
\hline & Chumbo & 0,0061 & 0,05 & 0,01 & \\
\hline & Mercúrio & 0,0008 & 0,002 & 0,0002 & \\
\hline \multirow{3}{*}{2014} & Cádmio & 0,0005 & 0,01 & 0,001 & \multirow{3}{*}{$\mathrm{mg} / \mathrm{L}$} \\
\hline & Chumbo & 0,0053 & 0,05 & 0,01 & \\
\hline & Mercúrio & 0,0021 & 0,002 & 0,0002 & \\
\hline \multirow{3}{*}{2015} & Cádmio & 0,0004 & 0,01 & 0,001 & \multirow{3}{*}{$\mathrm{mg} / \mathrm{L}$} \\
\hline & Chumbo & 0,0001 & 0,05 & 0,01 & \\
\hline & Mercúrio & 0,0011 & 0,002 & 0,0002 & \\
\hline \multirow{3}{*}{2016} & Cádmio & ND & 0,01 & 0,001 & \multirow{3}{*}{$\mathrm{mg} / \mathrm{L}$} \\
\hline & Chumbo & ND & 0,05 & 0,01 & \\
\hline & Mercúrio & ND & 0,002 & 0,0002 & \\
\hline
\end{tabular}

Legenda: V.M.P. - Valor Máximo Permitido. ND - Não Determinado.

Avaliando os parâmetros cádmio, chumbo e mercúrio a montante e a jusante do ponto de descarte do efluente da ETE Dr. Hélio Seixo de Brito no Rio Meia Ponte, observa-se que os VMP excedidos, foram nos mesmos anos e parâmetros. No ano de 2013, o cádmio a jusante diminuiu em relação ao resultado a montante e o mercúrio aumentou. Em 2014 e 2015, o mercúrio a jusante diminuiu com relação a montante.

Recebeu o resultado da análise do ano de 2015 do chorume do Aterro Sanitário de Goiânia, referente a lagoa anaeróbia e a lagoa facultativa, receptoras do chorume. Comparou-se os resultados em função da Resolução Conama $n^{\circ}$ 397/2008, esta altera alguns incisos do art. 34 da Resolução Conama n 357/2005 e a Resolução Conama $n^{\circ}$ 430/2011 complementa e altera a Resolução Conama $n^{\circ}$ 357/2005 (BRASIL, 2008a, 2011).

A Tabela 5 apresenta a análise do chorume da lagoa anaeróbia do Aterro Sanitário de Goiânia de 2015. Os parâmetros disponibilizados, cádmio e chumbo estão dentro do VMP pela Resolução Conama n 397/2008 e da Resolução Conama $n^{\circ} 430 / 2011$. 
TABELA 5 - Análise da lagoa anaeróbia do chorume do Aterro Sanitário de Goiânia referente ao ano de 2015.

\begin{tabular}{|c|c|c|c|c|}
\hline \multirow{2}{*}{ Ano } & Parâmetros & $\begin{array}{c}\text { Resultados Chorume } \\
\text { Lagoa anaeróbia }\end{array}$ & $\begin{array}{c}\text { VMP: CONAMA } \\
\mathbf{3 9 7 / 2 0 0 8} \text { CONAMA } \\
\mathbf{4 3 0 / 2 0 1 1}\end{array}$ & \multirow{2}{*}{ Unidade } \\
\hline \multirow{2}{*}{201} & Cádmio & 0,02 & 0,20 & \multirow{2}{*}{$\mathrm{mg} / \mathrm{L}$} \\
\cline { 2 - 4 } 5 & Chumbo & 0,19 & 0,50 & \\
\cline { 2 - 4 } & Mercúrio & ND & 0,01 & \\
\hline
\end{tabular}

Legenda: V.M.P. - Valor Máximo Permitido. ND - Não Determinado.

Na Tabela 6, os resultados no ano de 2015 dos parâmetros disponibilizados cádmio e chumbo do chorume da lagoa facultativa, proveniente do Aterro Sanitário de Goiânia, são comparados com a Resolução Conama n 397/2008 e da Resolução Conama n 430/2011.

TABELA 6 - Análise da lagoa facultativa do chorume do Aterro Sanitário de Goiânia referente ao ano de 2015.

\begin{tabular}{|c|c|c|c|c|}
\hline \multirow{2}{*}{ Ano } & Parâmetros & $\begin{array}{c}\text { Resultados Chorume } \\
\text { Lagoa facultativa }\end{array}$ & $\begin{array}{c}\text { VMP: CONAMA } \\
\text { 397/2008 CONAMA } \\
\mathbf{4 3 0 / 2 0 1 1}\end{array}$ & \multirow{2}{*}{ Unidade } \\
\hline \multirow{2}{*}{201} & Cádmio & 0,024 & 0,2 & \multirow{2}{*}{$\mathrm{mg} / \mathrm{L}$} \\
\cline { 2 - 4 } 5 & Chumbo & 0,22 & 0,5 & \\
\cline { 2 - 4 } & Mercúrio & ND & 0,01 & \\
\hline
\end{tabular}

Legenda: V.M.P. - Valor Máximo Permitido. ND - Não Determinado.

\section{Correlação entre as pilhas e baterias vendidas e recicladas}

O PARP, iniciou-se em novembro do ano de 2010, e expõe no sítio online o peso total de pilhas e baterias coletadas no Brasil desde o seu início. Então, no dia 8 de dezembro de 2017 o sítio descrevia um total de $12.637 .584,5 \mathrm{~kg}$. Tal peso é referente a 2595 dias de programa, no qual, dividindo o peso pela quantidade de dias tem-se a média estimada de coleta diária, 4.869,9747 kg/dia. Para análise comparativa, utilizou-se esta aferição para estimar o peso de pilhas e baterias coletadas e recicladas no Brasil no período de 2012 a 2016; 8.897.443,78 kg, conforme representado pela Tabela 7.

TABELA 7 - Estimativa da quantidade de pilhas e baterias recicladas entre 2012 a 2016 no Brasil.

\begin{tabular}{|c|c|c|c|}
\hline Período & Dias & Coleta & Estimativa \\
\hline $\begin{array}{c}\text { Novembro 2010 - 8 de } \\
\text { dezembro de 2017 }\end{array}$ & 2595 & $12.637 .584,50$ & \\
\hline $2012-2016$ & 1827 & A determinar & $4869,97 \times 1827=8.897 .443,78 \mathrm{~kg}$ \\
\hline
\end{tabular}

No dia 15 de junho de 2016 o PARP informou o peso total de $3.678,09 \mathrm{~kg}$ coletado do estado de Goiás, desde o seu início, nos 19 pontos de coleta. Tal período corresponde a 2054 dias, proporcionando uma média de 1,7906 kg/dia. 
Considerando o período de 2012 a 2016, 1827 dias, tem-se aproximação média de $3.271,4262 \mathrm{~kg}$, dados estes demonstrados pela Tabela 8 .

TABELA 8 - Estimativa da quantidade de pilhas e baterias recicladas entre 2012 a 2016 em Goiás.

\begin{tabular}{|c|c|c|c|}
\hline Período & Dias & Coleta & Estimativa \\
\hline $\begin{array}{c}01 / 11 / 2010- \\
15 / 06 / 2016\end{array}$ & 2054 & $3.678,09 \mathrm{~kg}$ & \\
\hline $2012-2016$ & 1827 & A determinar & $1,7906 \times 1827=3.271,4262 \mathrm{~kg}$ \\
\hline
\end{tabular}

Tem-se o peso das partes e peças para pilhas, baterias ou acumuladores elétricos, exceto para veículos, no Brasil referente ao período de 2010 a 2013, obtidos através do PIA-Produto e apresentado na Tabela 9. Os anos de 2014 a 2016, determinou-se através da Taxa Média de Crescimento em Intervalos Regulares de Tempo (rever Equação 1), conforme segue:

Taxa de crescimento $=31,62 \%$

TABELA 9 - Peso das partes e peças para pilhas, baterias ou acumuladores elétricos, exceto para veículos, no Brasil, de 2010 a 2013.

\begin{tabular}{|c|c|}
\hline Ano & Peso $(\mathbf{k g})$ \\
\hline 2010 & $769.758,00$ \\
\hline 2011 & $1.413 .191,00$ \\
\hline 2012 & $2.422 .274,00$ \\
\hline 2013 & $2.310 .274,00$ \\
\hline
\end{tabular}

Com a Taxa Média de Crescimento em Intervalos Regulares de Tempo, estimou-se o peso das partes e peças para pilhas, baterias ou acumuladores elétricos, referente aos anos de 2014 a 2016 apresentados na Tabela 10. Assim, tem-se os dados da pesquisa de 2012 a 2016.

TABELA 10 - Peso estimado de pilhas e baterias fabricadas e vendidas no Brasil entre 2012 a 2016.

\begin{tabular}{|c|c|c|c|}
\hline Ano & Taxa de Crescimento & Peso (kg) & Peso Total $(\mathrm{kg})$ \\
\hline 2012 & $31,62 \%$ & $2.422 .274,00$ & \multirow{5}{*}{$16.046 .421,84$} \\
\hline 2013 & $31,62 \%$ & $2.310 .274,00$ & \\
\hline 2014 & $31,62 \%$ & $3.040 .782,64$ & \\
\hline 2015 & $31,62 \%$ & $3.771 .291,28$ & \\
\hline 2016 & $31,62 \%$ & $4.501 .799,92$ & \\
\hline
\end{tabular}

Para estimar o percentual de pilhas e baterias recicladas no Brasil, comparouse os pesos de pilhas e baterias fabricadas e vendidas no período de 2012 a 2016 
em relação as que obtiveram como destinação final a reciclagem neste mesmo período, assim subtraiu-se o peso fabricado e vendido pelo peso reciclado e determinou-se o percentual representativo da reciclagem, como demonstrado na Tabela 11.

TABELA 11 - Estimativa de pilhas e baterias recicladas no Brasil entre 2012 a 2016.

\begin{tabular}{|c|c|c|c|c|}
\hline Período & Fabricado (kg) & Reciclado (kg) & Diferença (kg) & Percentual \\
\hline $2012-2016$ & $16.046 .421,84$ & $8.897 .443,78$ & $7.148 .978,06$ & $55,45 \%$ \\
\hline
\end{tabular}

Para estimar o peso de pilhas e baterias fabricadas e vendidas em Goiás, efetuou-se uma correlação em função da população do Brasil em relação a de Goiás, sendo que, segundo o Censo 2010 do IBGE, a população do Brasil é de 190.732.694 pessoas e também no IBGE, o Brasil em síntese, demonstra que a população de Goiás no último Censo (2010) é de 1.302.001 pessoas. Com isso, obteve-se o peso estimado de pilhas e baterias fabricadas e vendidas em Goiás no período de 2012 a 2016, como apresentado na Tabela 12.

TABELA 12 - Peso estimado de pilhas e baterias fabricadas e vendidas em Goiás entre 2012 a 2016.

\begin{tabular}{|c|c|c|c|c|}
\hline PERIOODO & \multicolumn{2}{|c|}{ BRASIL } & \multicolumn{2}{c|}{ GOIAS } \\
\hline & $\begin{array}{c}\text { Fabricad } \\
\text { o (kg) }\end{array}$ & População & Fabricado (kg) & População \\
\hline $2012-2016$ & $\begin{array}{c}16.046 .42 \\
1,83\end{array}$ & 190.755 .799 & $505.040,03$ & 6.003 .788 \\
\hline
\end{tabular}

Com o peso estimado de pilhas e baterias fabricadas e vendidas em Goiás e o peso das mesmas recicladas, obteve-se o percentual de pilhas e baterias recicladas em Goiás no período de 2012 a 2016, apresentado na Tabela 13.

TABELA 13 - Percentual de pilhas e baterias recicladas em Goiás entre 2012 a 2016.

\begin{tabular}{|c|c|c|c|c|}
\hline Período & $\begin{array}{c}\text { Fabricado } \\
(\mathbf{k g})\end{array}$ & $\begin{array}{c}\text { Reciclado } \\
\mathbf{( k g )}\end{array}$ & $\begin{array}{c}\text { Diferença } \\
(\mathbf{k g})\end{array}$ & Percentual \\
\hline $2012-2016$ & $505.040,03$ & $3.271,43$ & $501.768,61$ & $0,65 \%$ \\
\hline
\end{tabular}

\section{DISCUSSÃO}

As análises dos pontos de coleta avaliados encontram-se, em sua maioria, dentro do VMP estabelecidos pela legislação e resoluções pertinentes. Mas, é preciso se destacar para o fato de que a área na qual se encontra atualmente o Aterro Sanitário de Goiânia, começou a ser utilizada como disposição de RSU em 1983 (COMURG, 2016); tendo apenas 35 anos de deposição. As pilhas e baterias levam cerca de 100 anos (GRIPPI, 2006; SCDNR, 2017) logo as depositadas no aterro sanitário de Goiânia encontram-se em processo de decomposição e, desta forma, os teores de metais tóxicos tendem a se elevar com o decorrer dos anos. Diante do potencial tóxico dos metais presentes nestes resíduos e os impactos a saúde e ao meio ambiente, que afetam as comunidades e ao ecossistema, é fundamental o monitoramento por meio de análise dos metais para 
acompanhamento dos teores a jusante do ponto de descarte do efluente contendo chorume no Rio Meia Ponte, em função da concentração destes no chorume.

O Panorama dos Resíduos Sólidos no Brasil, organizado pela Associação Brasileira de Empresas de Limpeza Pública e Resíduos Especiais (ABELPE, 2016) apresenta a destinação final dos RSU em Goiás e nos demais estados, entre elas aterro sanitário, aterro controlado e deposito inadequado (DI), popularmente denominado lixão. O Panorama dos Resíduos Sólidos no Brasil (2016) apresenta a quantidade de municípios com iniciativas de coleta seletiva, apenas 30,4\%; enquanto esta deveria ser a principal forma de destinação final dos RSU.

De acordo com o Panorama dos Resíduos Sólidos no Brasil do período de 2012 a 2016, houve um crescimento no sistema de logística reversa das embalagens de agrotóxicos, embalagens de óleos lubrificantes e pneus apesar da publicação da Lei $n^{\circ} 12.305$, de 2 de agosto de 2010 que Institui a Política Nacional de Resíduos Sólidos, regulamentar que as pilhas e baterias deveriam estar incluídas no sistema de logística reversa., evidenciando a necessidade de expandir os programas de reciclagem das pilhas e baterias (ABRELPE, 2016) para o Brasil como um todo.

A correlação entre as pilhas e baterias portáteis fabricadas, comercializadas e recicladas, estima-se que no Brasil que cerca de 55,45\% das pilhas e baterias no período de 2012 a 2016 foram recicladas, entendendo que se produziu e comercializou $16.046 .421,84 \mathrm{~kg}$ e a reciclagem foi de $8.897 .443,78 \mathrm{~kg}$, restando então $7.148 .978,06 \mathrm{~kg}$, um peso significante sendo descartado de forma ambientalmente inadequada.

No estado de Goiás, comercializou-se cerca de 505.040,03 kg de pilhas e baterias no período de 2012 a 2016. Neste mesmo período, reciclou-se cerca de $3.271,43 \mathrm{~kg}$ destes resíduos, tendo cerca de $501.768,61 \mathrm{~kg}$ não reciclados. Esta diferença gera o percentual médio de $0,65 \%$ de pilhas e baterias recicladas. Com isso, tem-se $99,35 \%$ das pilhas e baterias sendo descartadas no resíduo comum.

Considerando esta realidade para a cidade de Goiânia, tem-se que as pilhas e baterias descartas no resíduo comum, são encaminhadas ao Aterro Sanitário de Goiânia; onde os resíduos contidos neste aterro geram chorume, sendo este encaminhado para tratamento juntamente com efluente doméstico na ETE Dr. Hélio Seixo de Brito. Esta ETE possui um tratamento primário avançado, que remove: os sólidos no gradeamento; a areia processo de desarenação; e o processo de coagulação e floculação forma os flocos gerados pela adição do coagulante e polímero, separando o lodo no decantador primário. Em seguida o efluente tratado é lançado no Rio Meia Ponte (SANEAGO, 2017).

Os resultados indicam uma tendência a elevação nos teores dos parâmetros cádmio, chumbo e mercúrio, decorrente do processo de decomposição das pilhas e baterias presentes no aterro sanitário, para o chorume tratado. Com isso, após o efluente contendo chorume passar pelo tratamento primário avançado da ETE, os metais potencialmente tóxicos estarão no lodo ou ainda no efluente final tratado.

O lodo pode ser utilizado na recuperação de áreas degradadas ou voltar para o Aterro Sanitário de Goiânia. No primeiro caso, irá acumular os metais potencialmente tóxicos no solo e no segundo pode gerar um ciclo crescente que potencializa a toxicidade, destacando que a utilização do lodo em solo agrícola é vantajoso, mas há precauções pois, é necessário monitorar os teores de elementos potencialmente tóxicos devido ao fato de que a toxicidade pode afetar diretamente 
as plantas, ocasionando perda de produtividade, expondo, até mesmo a morte além de efeitos indiretos, através da acumulação na cadeia alimentar, gerando problemas a saúde de homens e animais (NUVOLARI, 2011).

Os metais potencialmente tóxicos presentes no efluente final estudado, serão lançados no Rio Meia Ponte, comprometendo a qualidade das águas do rio que será utilizada nas $\mathrm{s}$ cidades e zonas rurais a jusante do ponto de descarte do efluente final, da ETE Dr. Hélio Seixo de Brito, causando um desequilíbrio natural.

\section{CONCLUSÃO}

O descarte ambientalmente inadequado de pilhas e baterias e a disposição nos Aterros Sanitários, caracteriza-se como uma condição potencialmente tóxica a saúde humana e ao meio ambiente devido ao tempo necessário para a decomposição e dispersão dos metais tóxicos que as compõem.

Sabendo que as pilhas e baterias possuem constituintes metais como cádmio $(\mathrm{Cd})$, chumbo $(\mathrm{Pb})$, mercúrio $(\mathrm{Hg})$, níquel $(\mathrm{Ni})$, lítio $(\mathrm{Li})$, zinco $(\mathrm{Zn})$ e manganês $(\mathrm{Mn})$, e que estes afetam diretamente a saúde humana e o meio ambiente, por meio da contaminação do meio biótico e abiótico, é necessário que se estabeleçam limites quanto aos teores de todos os componentes por terem indicativo de potencialidade tóxica, estabelecendo que todas pilhas e baterias fossem destinadas a reciclagem, o que minimizaria a possibilidade de disposição em aterros sanitários devido as estimativas de reciclagem de pilhas e baterias, que no período de 2012 a 2016, no Brasil e no estado de Goiás, foram de apenas $55,45 \%$ e $0,65 \%$, respectivamente, o que torna fundamental a implantação de medidas ambientalmente adequadas e economicamente viáveis para solucionar a problemática do descarte.

\section{REFERÊNCIAS}

ABINEE. Programa Abinee Recebe Pilhas. Associação Brasileira da Indústria Elétrica e Eletrônica. <http://www.gmcons.com.br/gmclog/admin/VisualizarPostosMapaCliente.aspx>.

ABNT. NBR 7039 Pilhas e acumuladores elétricos. Associação Brasileira de Normas Técnicas. Rio de Janeiro, RJ, Brasil, 1987.

ABRELPE. Panorama dos Resíduos Sólidos no Brasil. Associação Brasileira de Empresas de Limpeza Pública e Resíduos Especiais, p. 92, São Paulo, SP, 2016. BOCCHI, N.; FERRACIN, L. C.; BIAGGIO, S. R. Pilhas e Baterias: Funcionamento e Impacto Ambiental. Química Nova na Escola, v. 11, p. 3-9, 2000. Disponível em: http://qnesc.sbq.org.br/online/qnesc11/v11a01.pdf.

BRASIL. Lei $n^{\circ}$ 8.544, de 17 de outubro de 1978. Diário Oficial da República Federativa do Brasil, Poder Executivo, Brasília, DF, 1978.

BRASIL. Resolução $n^{\circ}$ 357, de 17 de março de 2005. Diário Oficial da República Federativa do Brasil, Brasília, DF, 2005.

BRASIL. Resolução $n^{\circ} 375$, de 29 de agosto de 2006. Diário Oficial da República Federativa do Brasil, Brasília, DF, 2006. 
BRASIL. Resolução Conama $n^{\circ}$ 397, de 3 de abril de 2008. Diário Oficial da República Federativa do Brasil, Brasília, DF, 2008.

BRASIL. Resolução Conama $n^{\circ} 401$, de 4 de novembro de 2008. Diário Oficial da República Federativa do Brasil, Brasília, DF, 2008.

BRASIL. Resolução $n^{\circ}$ 430, de 13 de maio de 2011. Diário Oficial da República Federativa do Brasil, Brasília, DF, 2011.

COMURG. Aterro Sanitário de Goiânia. Companhia de Urbanização de Goiânia. Goiânia, 2016.

FARRIS, P. W.; BENDLE, N. T.; PFEIFER, P. E.; REIBSTEIN, D. J. Marketing Metrics: The Definitive Guide to Measuring Marketing Performanc. 2. ed. Pearson Prentice Hall, 2010.

GRIPPI, S. Lixo Reciclagem e sua História. Interciência, 2. ed. Rio de Janeiro, RJ, 2006.

IBGE. Pesquisa Industrial Anual - Produto, PIA-Produto. Instituto Brasileiro de Geografia e Estatística, 2016. Disponível em: <https://www.ibge.gov.br/estatisticasnovoportal/economicas/industria/9044-pesquisa-industrial-anual-produto.html>.

MONTEIRO, J. H. P.; ZVEIBIL, V. Z.; FIGUEIREDO, C. E. M.; MAGALHÃES, A. F.; MELO, M. A. F. de. et al. Manual Gerenciamento Integrado de Resíduos Sólidos. Instituto Brasileiro de Administração Municipal (IBAM), Rio de Janeiro, RJ, 2001.

NUVOLARI, A. Esgoto sanitário: coleta, transporte, tratamento e reuso agrícola. Blucher, São Paulo, 2011.

ORSOLON, M. Hora de reciclar. Potência, p. 28-37, Ano VI. Edição nํ 61, 2010. Disponível em: http://www.clrb.com.br/site/us/arquivos/05_Mercado0Agosto.pdf.

REIDLER, N. M. V. L.; GÜNTHER, W. M. R. Impactos ambientais e sanitários causados por descarte inadequado de pilhas e baterias usadas. Revista Limpeza Pública. v. 60, p. 20-26, 2003. Disponível em: http://www.ablp.org.br/acervoPDF/01_LP60.pdf.

SANEAGO. ETE Dr. Hélio Seixo de Britto. Saneamento de Goiás. Disponível em: <http://www.saneago.com.br/2016/\#esgoto>. Acesso em: 6 set. 2017.

SCDNR. How Long Does It Take - State of Decomposition. South Carolina Department of Natural Resources. Disponível em: <http://www.dnr.sc.gov/up2u/decompose.html>. Acesso em: 3 mar. 2018. 